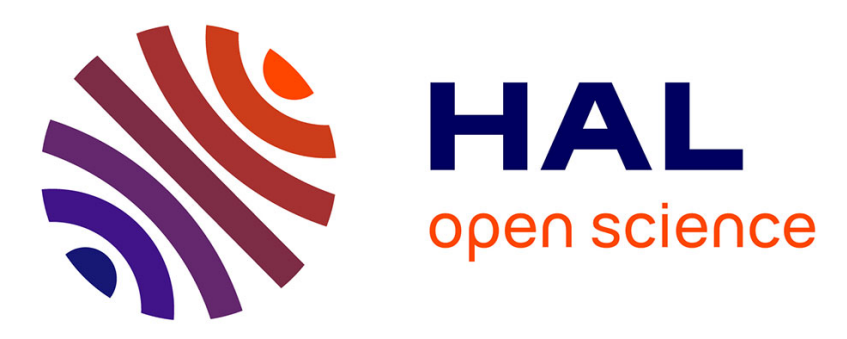

\title{
Micromoulding of three-dimensional photonic crystals on silicon substrates
}

\author{
Patrick Ferrand, M. J. Minty, M. Egen, J. Ahopelto, R. Zentel, S. G. \\ Romanov, C. M. Sotomayor Torres
}

\section{To cite this version:}

Patrick Ferrand, M. J. Minty, M. Egen, J. Ahopelto, R. Zentel, et al.. Micromoulding of threedimensional photonic crystals on silicon substrates. Nanotechnology, 2003, 14 (2), pp.323-326. 10.1088/0957-4484/14/2/343 . hal-00272386

\section{HAL Id: hal-00272386 \\ https://hal.science/hal-00272386}

Submitted on 1 Mar 2016

HAL is a multi-disciplinary open access archive for the deposit and dissemination of scientific research documents, whether they are published or not. The documents may come from teaching and research institutions in France or abroad, or from public or private research centers.
L'archive ouverte pluridisciplinaire HAL, est destinée au dépôt et à la diffusion de documents scientifiques de niveau recherche, publiés ou non, émanant des établissements d'enseignement et de recherche français ou étrangers, des laboratoires publics ou privés. 


\title{
Micromoulding of three-dimensional photonic crystals on silicon substrates
}

\author{
P. Ferrand and M. J. Minty \\ Institute of Materials Science and Department of Electrical and Information Engineering, \\ University of Wuppertal, Gauss-Str. 20, D-42097 Wuppertal, Germany
}

\section{Egen}

Institute for Organic Chemistry, Department of Chemistry and Pharmacy, University of Mainz, Duesbergweg 10-14, D-55099 Mainz, Germany

\section{J. Ahopelto}

VTT Centre for Microelectronics, P.O. Box 1208, FIN-02044 VTT, Finland

\section{R. Zentel}

Institute for Organic Chemistry, Department of Chemistry and Pharmacy, University of Mainz, Duesbergweg 10-14, D-55099 Mainz, Germany

S. G. Romanov and C. M. Sotomayor Torres

Institute of Materials Science and Department of Electrical and Information Engineering, University of Wuppertal, Gauss-Str. 20, D-42097 Wuppertal, Germany 
The growth of three-dimensional photonic crystals ( $\mathrm{PhCs}$ ) on patterned silicon substrates is reported. It is shown that deep trenches can be uniformly filled by a self-assembly of polymer microspheres, in a close-packed face-centered cubic lattice. The crystalline quality is compared for different channel widths. These observations are confirmed by optical reflectance measurements in the visible range, showing a bandwidth of enhanced reflection. The possibility to detach the $\mathrm{PhC}$, i.e., to use the substrate as a mould is also demonstrated. The potential of this approach for building complex $\mathrm{PhC}$-based complex architectures is discussed.

42.70.Qs, 81.16.Dn, 42.70.Jk

\section{Introduction}

Photons interact with materials with a periodic variation of the index of refraction in a similar way to electrons with crystalline solids. Due to the improvement they provide in

terms of emission control ${ }^{1}$, guiding $^{2}$, as well as dispersion engineering ${ }^{3}$, the former called photonic crystals (PhCs) are expected to be elementary bricks of a future generation of opto-electronic devices of reduced size, combining high integration and high speed processing ${ }^{4}$. However, since a high refractive index contrast, as well as submicrometer feature sizes are required, the fabrication of such three-dimensional (3D) PhCs designed for the optical wavelengths is still a technological challenge.

In this context, much attention is paid to opals, i.e., photonic crystals made of close packed monodisperse microspheres ${ }^{5}$. Because their realisation is based on self-assembly, 
the fabrication process is relatively cost-efficient, and can be extended to the large scale required by mass production. Moreover, the index contrast can be tailored by filling the voids between the balls ${ }^{6}$, and films of controlled thickness with single crystal domains of several $\mathrm{mm}^{2}$ can be grown ${ }^{7}$. However, future functional devices will need complex $\mathrm{PhC}$ architectures, and therefore it is essential to be able to structure the crystal itself at the microscopic scale.

One way to achieve this goal is to control the crystal growth. The deposition can be electrically driven, using charged spheres and a locally charged substrate ${ }^{8}$, but this technique is limited to a few layers. Another promising way is the use of patterned substrates. Grooves ${ }^{9}$ or pits $^{10}$ can trap spheres at predefined locations or, at larger scale, the growth of the $\mathrm{PhC}$ can be restricted in microscopic planar capillaries ${ }^{11}$, or arbitrary complex deep structures ${ }^{12}$.

In this article, our recent work on self-assembly of 3D PhC on deep etched structures in silicon wafers is reported. First the experimental details for preparation and characterisation of samples are given. Then the results of crystal growth in various geometries are presented, and these structural observations are complemented by optical measurements. The issue of cracks is discussed and the possibility to use them to detach the crystal from the substrate is demonstrated. 


\section{Experimental details}

The (100) silicon wafers were etched in an inductively coupled plasma reactor, to typical etch depths between 7 and $10 \mu \mathrm{m}$. They were cleaned by a standard process, hydrophilised in a $\mathrm{H}_{2} \mathrm{O}_{2}(35 \%): \mathrm{NH}_{3}(25 \%): \mathrm{H}_{2} \mathrm{O}(1: 1: 5)$ bath for 3 hours, and rinsed in deionised water. The sedimentation was performed by drawing up the wafer in a vertical position with a velocity of about $300 \mathrm{~nm} / \mathrm{s}$ from a $3 \mathrm{wt} \%$ suspension of monodisperse polymethylmethacrylate (PMMA) spheres of diameter $280 \mathrm{~nm}$ or $325 \mathrm{~nm}$, prepared following the routine described elsewhere ${ }^{13}$. All processes were carried out at room temperature. Optical reflectance was measured using a Dilor XY 800 triple spectrometer equipped with a microscope, in a front white-light illumination configuration, through an intentionally low numerical aperture $(0.25)$ objective $(\times 10$ magnification). Care was taken to use a spatial filter in order to select from the surface of the sample an effective area of $50 \times 50 \mu \mathrm{m}^{2}$. Spectra were corrected by the response of the whole optical system. Prior to their observation by a Philips XL30 scanning electron microscope (SEM), the samples were sputtered with a thin film $(10 \mathrm{~nm})$ of gold.

\section{Results and discussion}

\section{Control of growth}

In order to obtain a film of uniform thickness, the $\mathrm{PhC}$ was grown in a vertical geometry ${ }^{7}$, as illustrated in Fig. 1a. Adjusting the lifting speed provided an additional control of the thickness ${ }^{14,15}$, in order to match the trench depth. In addition, since the deposition of

spheres takes place at the top of the meniscus ${ }^{14,16}$, which is higher within the trenches due 
to stronger capillary forces, the colloids are drained there and unetched silicon remains sparsely covered, as illustrated in Fig. $1 \mathrm{~b}$.

\section{Structural properties}

A SEM micrograph of a typical patterned substrate before the $\mathrm{PhC}$ growth is shown in Fig. 2a. Here the pattern is constituted by a set of $40-\mu \mathrm{m}$ wide hexagons, etched to a depth of $7 \mu \mathrm{m}$. Hexagons have been chosen because their 120 degree angles match the crystallographic symmetry of the close package. Fig. $2 b$ shows the sample after growth. Etched regions (appearing dark) are completely filled by $325 \mathrm{~nm}$ balls, and form a wellordered 3D PhC of about 25 layers, whereas unetched regions (light) are just covered by one or two layers, as it can be seen in the close-up in Fig. 2c.

The filling takes place also in trenches narrower than $1 \mu \mathrm{m}$, as illustrated in Fig. 3 . The ordering is relatively good and it can be seen on the bottom channel that the slight increase of width gives rise to a defect line, because it is no longer commensurable with the sphere size. The study of ordering as a function of depth is under current investigations. The main obstacle we have to overcome is the damage to the $\mathrm{PhC}$ when cleaving the sample.

Restricting us to the case of channels, the influence of the size on the structural properties has been also investigated. In Fig. 4a, a top view SEM micrograph of $\mathrm{PhC}$ in a $100-\mu \mathrm{m}$ wide channel is shown. One can clearly see an almost perfect closed package of the 280 nm spheres, in a face-centred cubic (fcc) lattice of $396 \mathrm{~nm}$ lattice constant with the [111] 
growth direction perpendicular to the surface of the substrate, similar to what is usually obtained on flat substrates. Fig. $4 \mathrm{~b}$ shows a set of $10-\mu \mathrm{m}$ wide channels. In this case, it is noticeable that the order is perturbed by some fluctuations of the lattice parameter.

\section{Optical properties}

These structural observations were complemented by absolute reflectance measurements carried out perpendicular to the sample surface, in regions illustrated in Fig. 4a and 4b, respectively. Both spectra in Fig. 5 show Fabry-Perot interference fringes as a evidence for the uniform total optical thickness of the $\mathrm{PhC}$, and a Bragg reflection at wavelengths around $620 \mathrm{~nm}$, as a proof of the periodic nature of the $\mathrm{PhC}$. The wavelength of the Bragg reflection and the relative bandwidth $\Delta \lambda / \lambda=5.5 \%$ in the wide channel case (Fig. 5, thick line), are in good agreement with the theoretical estimate of the stop-band along the [111] direction for PMMA spheres of refractive index $n=1.489$, close-packed in a fcc lattice (filling fraction $74 \%)^{17}$. The Bragg peak of the sample grown on the narrow channel (Fig. 4b) appears less intense and slightly broader (Fig. 5, thin line, $\Delta \lambda / \lambda=$ 8.5\%). This is a consequence of the slight disorder mentioned above, which takes place both in the plane and in depth. At the moment, the reasons for this remain unclear and are under investigation.

\section{Issue of cracks}

Finally, it is observed that the location of cracks is also strongly affected by the finite trench size. Indeed, these cracks are probably a consequence of strains induced by the shrinkage of the colloidal crystal ${ }^{18}$. In the case of opal grown on an unpatterned substrate 
or in a wide trench, these cracks are almost randomly distributed over the surface. Nevertheless, a typical size of crack-free domains can be empirically predicted. In our specific case, Fig. 4a shows that this size is about a couple of hundred square micrometers. The patterned substrate is in practice a rigid frame, which, for trenches smaller than the crack-free typical size, gives rise to large strains. This result in cracks appearing only at the opal-substrate interfaces. This gives a guarantee of a structure free of cracks, at least in volume. This is clearly visible in Fig. 2b, where cracks are located along side walls.

\section{Detached structures}

Moreover, more than defects, these cracks are of practical interest, since they are not exclusively located along side walls but also at the bottom interface. They can be used to detach the opal structure from the substrate ${ }^{12}$. For this purpose, an adhesive tape was placed on the sample surface, and carefully released as illustrated in Figs. 6a and 6b. A top view SEM micrograph of the detached structure is shown in Fig. 7. The result resembles an elongated brick, of cross section about of $10 \times 10 \mu \mathrm{m}^{2}$, showing a straight edge and flat sides. The order seen on the top side corresponds to the early stage of the crystallisation, occurring at the bottom of the trench. This provides a further proof of the good global crystalline quality of the sample. The slight damage at the top edge of the crystal is due to the crude process used in this first attempt.

This approach, using the substrate as a mould and releasing the $\mathrm{PhC}$ after sedimentation, is a promising way to overcome some measurement challenges of 3D PhCs. For instance, 
detached structures can be investigated from the lateral sides, e.g., in and out-coupling for waveguide measurements, without requiring sawing and polishing. Moreover, by suspending the crystal, emission studies avoiding the critical influence of the substrate will be possible. Lastly, this technique may allow the construction of multilayer circuits, as in microelectronics. In our case, the construction would need two steps. i) Crystallization of each PhC circuit layer separately, using the structured Si substrates as a mould and ii) unmoulding and stacking. Figure $6 \mathrm{c}$ illustrates an example of complex PhC multilayer architecture, which could be realized by means of this process.

\section{Conclusion}

In summary, 3D PhC moulding using deeply etched silicon wafers has been reported. SEM observations showed a uniform filling of the trenches, as well as a close-packed ordering in a fcc lattice. These observations were confirmed by optical measurements, showing Fabry-Perot fringes as well as a Bragg reflection, the spectral position and width of which agreed with theoretical calculations. A slight disorder was observed in the case of the narrowest trenches. It was noticed that cracks occur preferably close the PhCsubstrate interface, giving the possibility to detach the structure from the substrate.

The authors acknowledge the support of the German Research Council (DFG) Priority Program SPP 1113 "Photonic Crystals" and of the EU IST Project PHOBOS Grant No. 19009. 


\section{FIGURES}

(a)

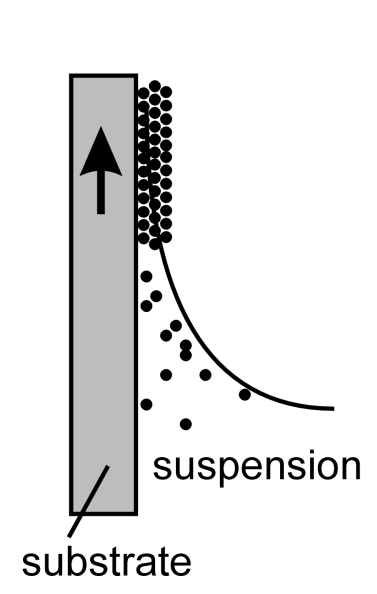

(b)

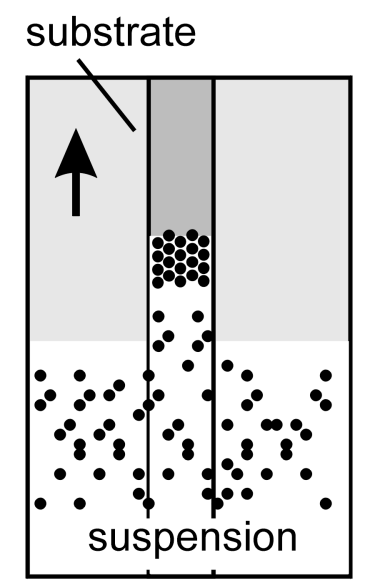

Fig. 1. (a) Schematic view of the geometry used for the $\mathrm{PhC}$ growth (side view).

Capillary forces drive spheres to the top on the meniscus. The film thickness is controlled by the concentration of the suspension, as well as by the lifting speed. (b) Case of a patterned substrate. Balls are drained into the trenches because the meniscus is higher. 

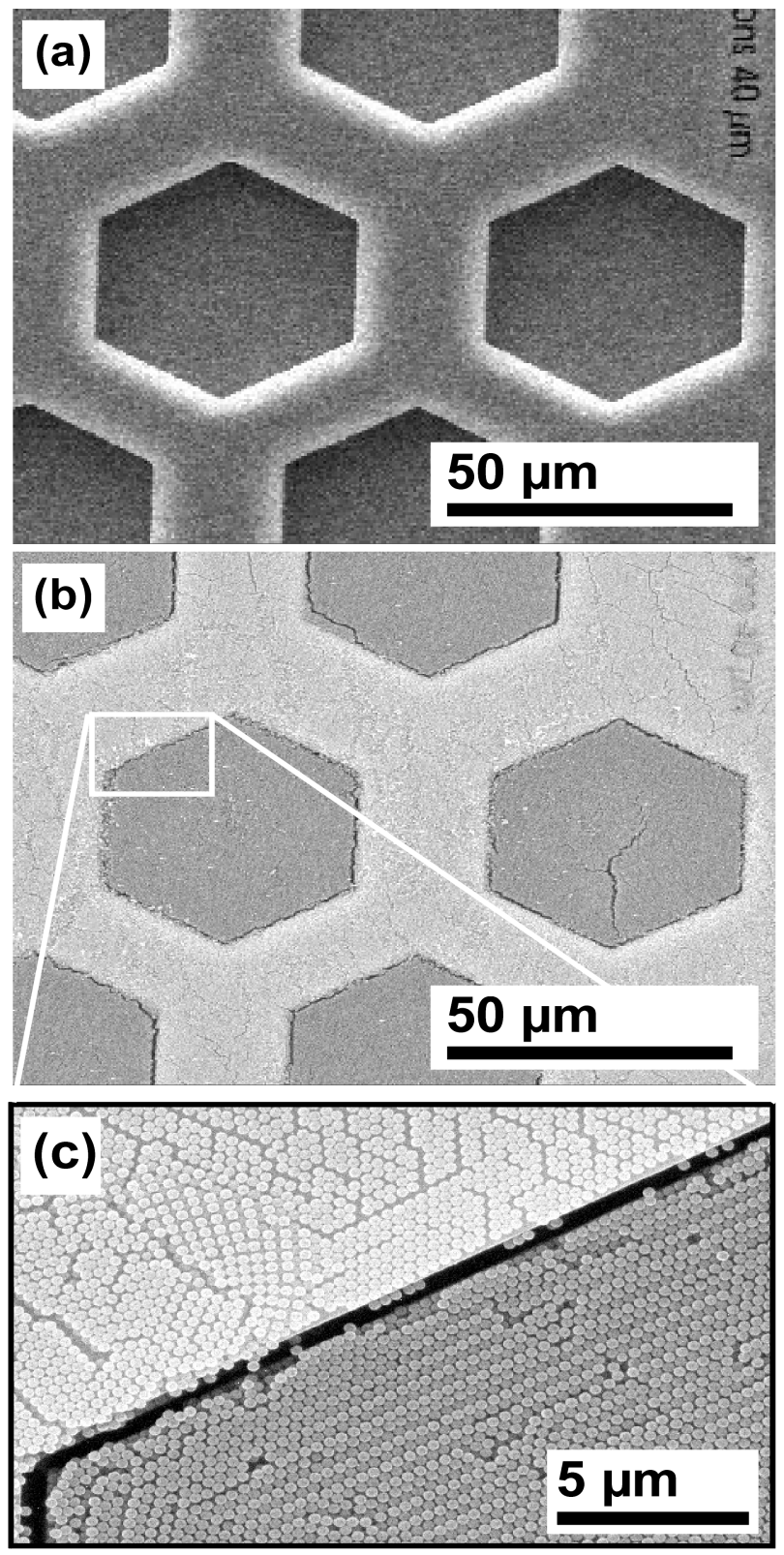

Fig. 2. (a) Top view SEM micrograph of a patterned substrate prior to the PhC growth. Etch depth is $7 \mu \mathrm{m}$. (b) Same view after growth. A 7- $\mu \mathrm{m}$ thick $\mathrm{PhC}$ fills dark regions, whereas light regions are just covered by one or two layers. (c) Close-up. 


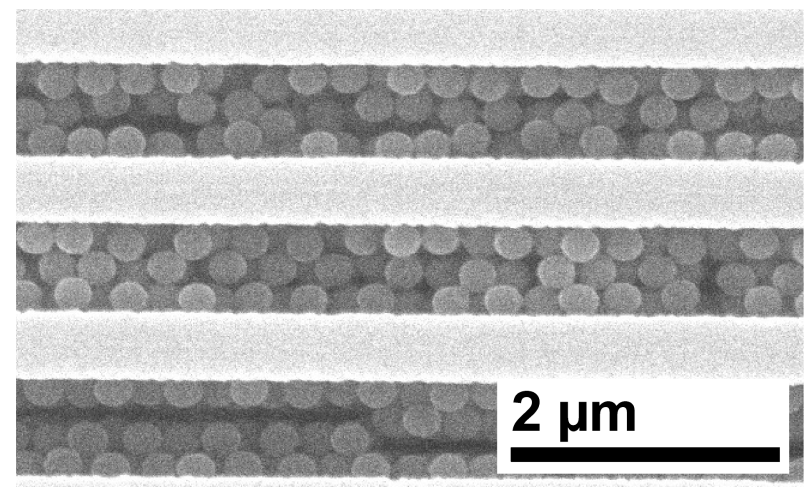

Fig. 3. Top view SEM micrograph showing that the PhC has grown even in narrow channels (less than $1 \mu \mathrm{m}$ ). Note that bottom channel is slightly wider. 

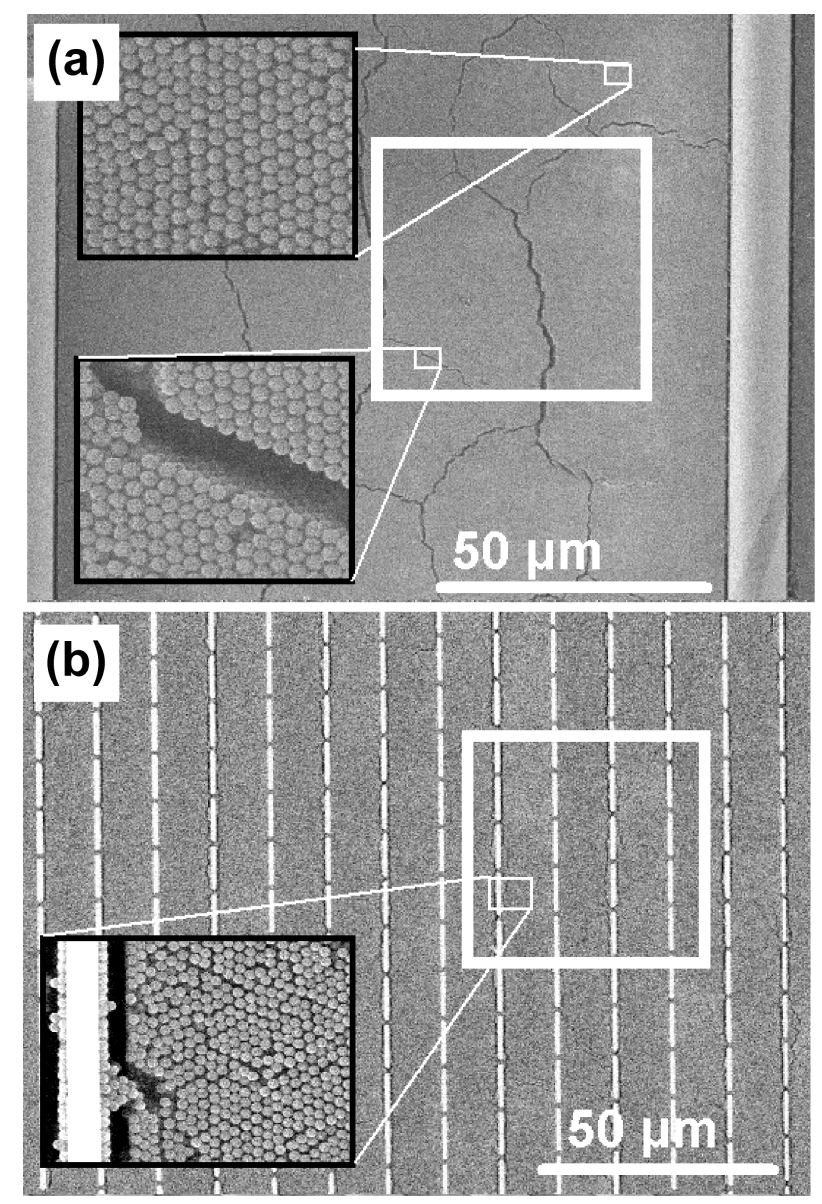

Fig. 4. Top view SEM micrographs showing the influence of the trench width on the crystal ordering. (a) Wide case $(100 \mu \mathrm{m})$. (b) Set of narrower $(10 \mu \mathrm{m})$ trenches. Insets are close-ups. 


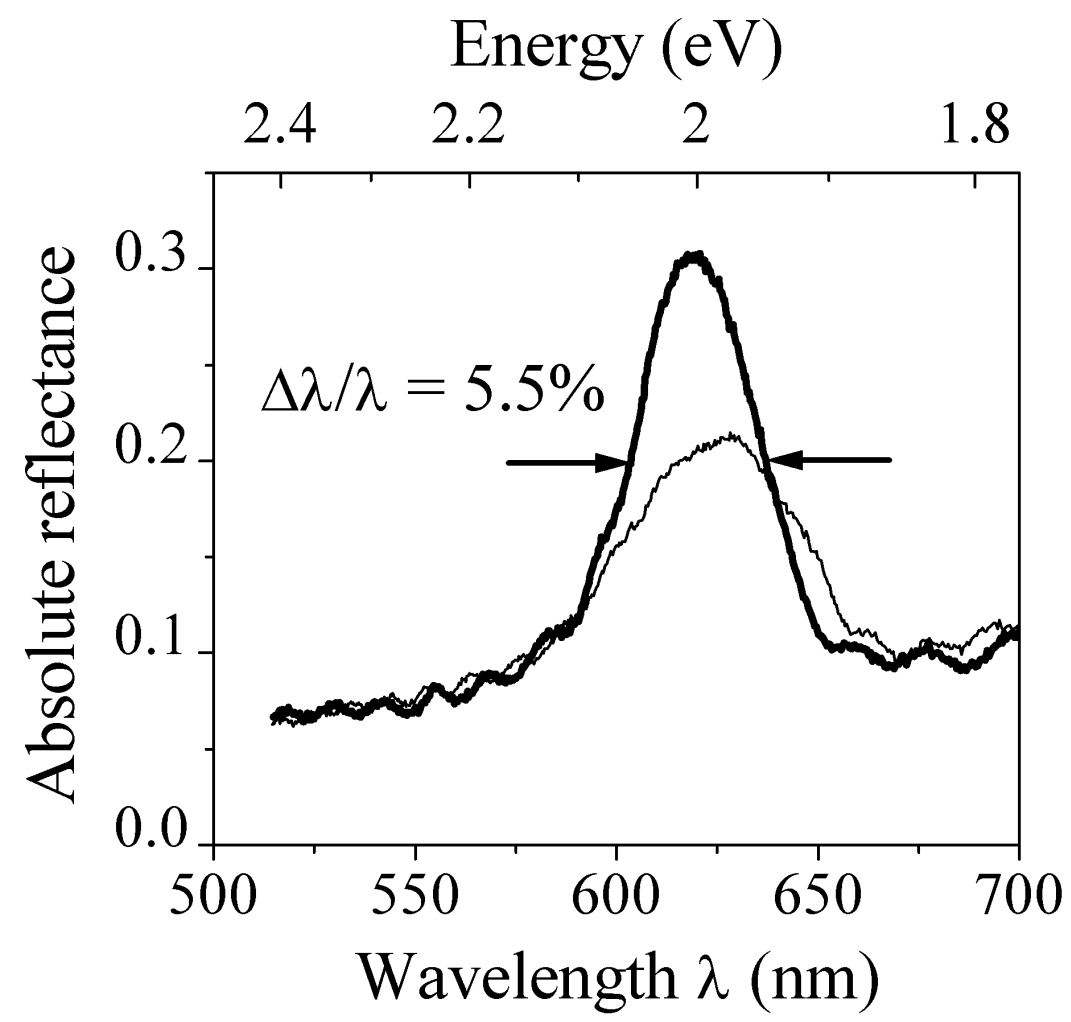

Fig. 5. Normal incidence absolute reflectance spectra, measured in regions indicated in white squares in Figs. 4a (thick line) and $4 b$ (thin line). 
(a) $/^{\text {adhesive tape }}$

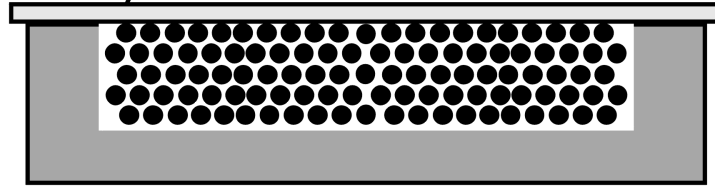

(b)

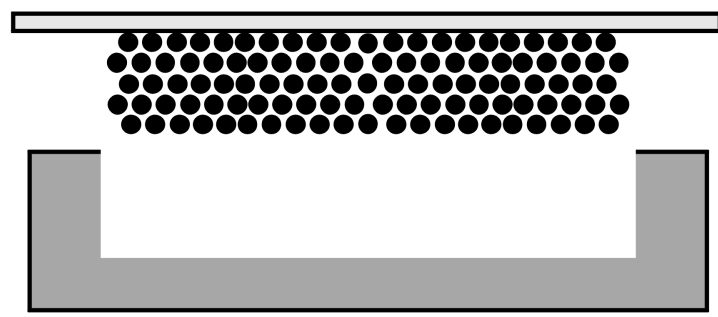

(c)

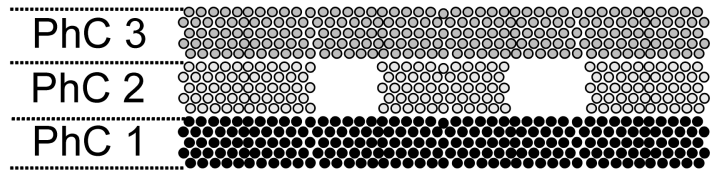

Fig. 6. Scheme illustrating the technique to detach the PhC from the substrate. (a) Step 1:

An adhesive tape is moderately pressed on the sample. (b) Step 2 : The $\mathrm{PhC}$ is released carefully. (c) Example (side view) of a complex $\mathrm{PhC}$ architecture that could be realized by stacking several pre-moulded PhCs (called here PhC1, etc.) 


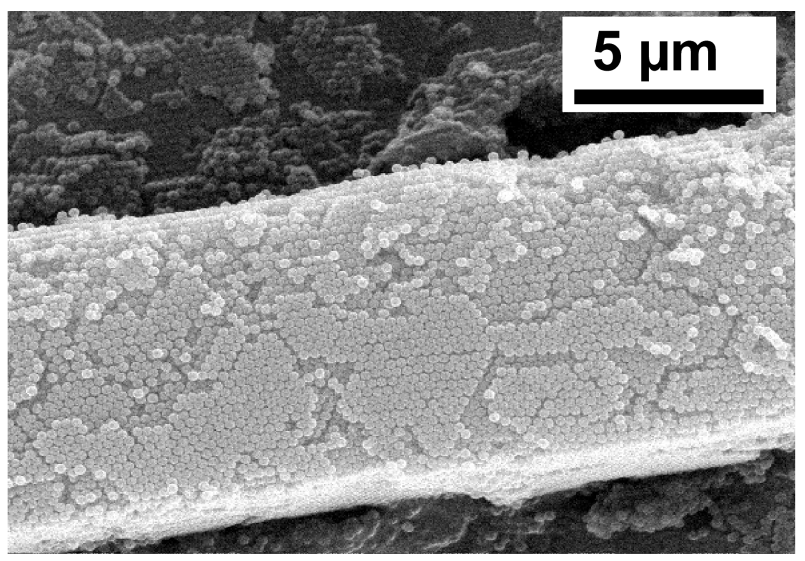

Fig. 7. Top view SEM micrograph of the detached structure. 


\section{REFERENCES}

${ }^{1}$ E. Yablonovitch, Phys. Rev. Lett. 58, 2059 (1987).

${ }^{2}$ A. Mekis, J. C. Chen, I. Kurland, S. Fan, P. R. Villeneuve and J. D. Joannopoulos, Phys. Rev. Lett. 77, 3787 (1996).

${ }^{3}$ B. Gralak, S. Enoch and G. Tayeb, J. Opt. Soc. Am. A 17, 1012 (2000).

${ }^{4}$ J. D. Joannopoulos, P. R. Villeneuve and S. Fan, Nature 386, 143 (1997).

${ }^{5}$ V. N. Astratov, V. M. Bogomolov, A. A. Kaplyanskii, A. V. Prokofiev, L. A.

Samoilovich, S. M. Samoilovich and Y. A. Vlasov, Nuovo Cimento 17D, 1349 (1995).

${ }^{6}$ Y. A. Vlasov, X. Z. Bo, J. C. Sturm, and D. J. Norris, Nature 414, 289 (2001).

${ }^{7}$ P. Jiang, J. F. Bertone, K. S. Hwang and V. L. Colvin, Chem. Mater. 11, 2132 (1999).

${ }^{8}$ E. Kumacheva, R. K. Golding, M. Allard and E. H. Sargent, $A d v$. Mater. 14, 221 (2002).

${ }^{9}$ Y. H. Ye, S. Badilescu, V. V. Truong, P. Rochon and A. Natasohn, Appl. Phys. Lett. 79, 872 (2001).

${ }^{10}$ G. A. Ozin and S. M. Yang, Adv. Funct. Mater. 11, 95 (2001) ; Y. Yin and Y. Xia, Adv. Mater. 14, 605 (2002).

${ }^{11}$ S. M. Yang, H. Míguez and G. A. Ozin, Adv. Funct. Mater. 12, 425 (2002).

${ }^{12}$ P. Ferrand, M. Egen., B. Griesebock, J. Ahopelto, M. Müller, R. Zentel, S. G. Romanov and C. M. Sotomayor Torres, Appl. Phys. Lett. 81, 2689 (2002).

${ }^{13}$ M. Müller, R. Zentel, T. Maka, S. G. Romanov and C. M. Sotomayor Torres, 
Chem. Mater. 12, 2508 (2000).

${ }^{14}$ Z. Z. Gu, A. Fujishima and O. Sato, Chem. Mater. 14, 760 (2002).

${ }^{15}$ M. Egen, B. Griesebock, R. Zentel, P. Ferrand, S. G. Romanov and C. M. Sotomayor Torres, unpublished.

${ }^{16}$ J. Aizenberg, P. V. Braun and P. Wiltzius, Phys. Rev. Lett. 84, 2997 (2000).

${ }^{17}$ S. G. Romanov, T. Maka, C. M. Sotomayor Torres, M. Müller, R. Zentel, D. Cassagne, J. Manzanares-Martinez and C. Jouanin, Phys. Rev. E 63, 056603 (2001).

${ }^{18}$ B. Griesebock, M. Egen, and R. Zentel, Chem. Mater. 14, 4023 (2002). 